\title{
ASPECTOS HISTOLÓGICOS DA UNIÃO DA ENXERTIA HIPOCOTILEDONAR DO MARACUJAZEIRO-AMARELO ${ }^{1}$
}

\author{
GERALDO COSTA NOGUEIRA FILHO ${ }^{2}$, GIVANILDO RONCATTO 3 , \\ CARLOS RUGGIERO ${ }^{4}$, JOÃO CARLOS DE OLIVEIRA ${ }^{4}$, EUCLIDES BRAGA MALHEIROS ${ }^{4}$, \\ CARLOS FERREIRA DAMIÃO FILHO
}

RESUMO - O objetivo deste trabalho foi verificar, um mês após a realização da enxertia hipocotiledonar, a conexão entre os tecidos vasculares do enxerto e do porta-enxerto e diferenças anatômicas na formação da união da enxertia entre os sete porta-enxertos. Coletaram-se amostras da região de enxertia de duas mudas de cada combinação enxerto/porta-enxerto. As regiões da enxertia foram fixadas, desidratadas em série alcoólica, incluídas em parafina, emblocadas e seccionadas em micrótomo. As secções obtidas foram montadas em lâminas de vidro, desparafinizadas, coradas com safranina e novamente desidratadas, obtendo-se lâminas histológicas permanentes. Cerca de 800 secções foram observadas e analisadas sob microscópio óptico e fotomicrografadas. Não se verificou diferença anatômica na formação da união da enxertia entre os sete porta-enxertos, e um mês após a realização da enxertia, a conexão entre os tecidos vasculares do enxerto e do porta-enxerto era observável.

Termos para Indexação: Passiflora spp. porta-enxerto, fotomicrografia, propagação vegetativa, histologia.

\section{HISTOLOGICAL ASPECTS OF THE HIPOCOTILEDONAR GRAFT UNION OF THE YELLOW PASSION FRUIT}

\begin{abstract}
The objective of this work was to observe, one month after the hypocotyledonary grafting, the connection between the vascular tissues of the graft, the rootstock and anatomical differences in the formation of the graft union among the seven rootstocks. Samples were collected from the region of grafting of two seedlings from each graft/rootstock combination. The regions of the graft were fixed, dehydrated in alcohol series, embedded in paraffin, blocks processing and sectioned in microtome. The sections obtained were mounted on glass slides, disparafinned, stained with Safranin and dried again, resulting in permanent histological slides. Approximately 800 sections were observed and analyzed by optical microscope and photomicrographed. There was anatomical difference in the formation of the graft union among the seven rootstocks, and one month after, the connection between the graft and vascular tissues of the rootstock was observable.
\end{abstract}

Index terms: Passiflora spp., rootstock, photomicrography, vegetative propagation, histology.

\section{INTRODUÇÃO}

A busca constante de inovações, com a finalidade da obtenção de mudas de qualidade, em um menor espaço de tempo, justifica, per se, o uso de novas tecnologias. Com isso, faz-se necessário o desenvolvimento e a adoção de técnicas que venham a aprimorar aquelas já existentes, visando ao desenvolvimento de métodos alternativos e inovadores para a fruticultura (OLIVEIRA, 2002).

A enxertia em maracujazeiro é uma prática recente ainda não incorporada como usual na cultura, devido a oscilações quanto ao pegamento e observações quanto ao desenvolvimento das plantas no campo. A enxertia hipocotiledonar pode ser uma alternativa interessante ao processo.

A enxertia é vista como a arte de inserir a parte de uma planta em outra planta, de tal maneira que as duas constituam uma unidade e ambas continuem seu crescimento (OLIVEIRA et al., 2002).

A união do enxerto é a base da enxertia, que se dá pelo entrelaçamento do tecido caloso, oriundo do câmbio do porta-enxerto e do enxerto. Essas células do calo, que são parenquimatosas, diferenciam-se em novo tecido cambial que, por sua vez, continua a diferenciação, formando nova conexão viva,

\footnotetext{
1'(Trabalho 146-09). Recebido em: 15-06-2009. Aceito para publicação em 07-12-2009.

${ }^{2}$ In memorian.

${ }^{3}$ Pesquisador A - Embrapa Acre. Rodovia BR 364 km 14, Zona Rural, Cep 69901180. Rio Branco-AC. E-mail: givanildo@cpafac.embrapa.br ${ }^{4}$ Prof. Titular da Unesp/Fcav. Via de acesso Paulo Donato Castellane, s/n Cep 14884-900 Jaboticabal-SP. E-mail: ruggiero@fcav.unesp.br jocaoliv@fcav.unesp.br; euclides@fcav.unesp.br; damiao@fcav.unesp.br
} 
em crescimento entre o porta-enxerto e o enxerto (JANICK, 1966).

$\mathrm{O}$ crescimento secundário e a atividade cambial estão geralmente associados ao fenômeno da cicatrização e da formação da união durante a enxertia. Lesões em folhas, raminhos jovens e outras partes da planta que não apresentam crescimento secundário, resultam geralmente na formação de uma cicatriz - deposição de substâncias que parecem proteger a superfície da dissecação e de lesões externas - e desenvolvimento de periderme a partir de células vivas subjacentes à cicatriz. Quando ramos ou troncos com crescimento secundário sofrem lesões, a formação da periderme é precedida pelo desenvolvimento do calo, um tecido parenquimático resultante da proliferação de várias células próximas à superfície da ferida. $\mathrm{O}$ calo também fornece o tecido através do qual se restaura a continuidade cambial, se foi seccionada pela lesão (ESAU, 1974).

O estabelecimento das ligações nos enxertos envolve fenômenos semelhantes aos associados à cicatrização. Os tecidos do calo formam-se a partir do porta-enxerto e do enxerto e preenchem o espaço entre ambos, e os respectivos câmbios tornam-se contínuos pela diferenciação do câmbio de conexão, a partir das células do calo. A ligação dos câmbios, quando o porta-enxerto e o enxerto são postos em contato, facilita o estabelecimento da conexão cambial (ESAU, 1974).

O objetivo deste trabalho foi verificar, um mês após a realização da enxertia, a conexão entre os tecidos vasculares do enxerto e do porta-enxerto e diferenças anatômicas na formação da união da enxertia entre os sete porta-enxertos.

\section{MATERIAL E MÉTODOS}

A primeira fase foi realizada no setor de fruticultura do Departamento de Produção Vegetal e a segunda, no Laboratório de Anatomia e Morfologia Vegetal do Departamento de Biologia Aplicada à Agropecuária, ambas as estruturas pertencentes à Faculdade de Ciências Agrárias e Veterinárias Câmpus de Jaboticabal, da Universidade Estadual Paulista.

Na primeira fase, janeiro e fevereiro/2002, trinta dias após a enxertia, foram coletados e fixados dois exemplares de cada porta-enxerto e retirada a região da enxertia, cortando-se cerca de $0,5 \mathrm{~cm}$ abaixo e acima da mesma.

A segunda fase, realizada em janeiro/2003, constituiu-se na confecção de lâminas histológicas permanentes e seu registro fotográfico, em microscópio óptico. A confecção de lâminas histológicas permanentes consistiu das etapas de fixação, desidratação, inclusão em parafina, seccionamento, montagem das secções, desparafinização, coloração, nova desidratação e, por fim, da aposição das lamínulas.

\section{a)Fixação}

Após coletarem-se os materiais, cada um foi acondicionado separadamente em um vidro contendo FAA (álcool etílico 95\%, ácido acético glacial, formalina e água destilada na proporção 5:0,5:1:3,5) para sua fixação e conservação, segundo metodologia indicada por Johansen (1940).

\section{b)Desidratação}

A desidratação foi efetuada em TBA (álcool butírico terciário), seguindo a metodologia descrita por Johansen (1940). A série gradual de álcoois utilizados e os passos adotados estão descritos na Tabela 1

\section{c)Inclusão em parafina}

Após a desidratação, procedeu-se a inclusão dos tecidos em Paraplast (LAAD Research Industries, Inc. P.O. Box 1005, Burlong, Vemont 054002, USA). A solução TBA (álcool butírico terciário) do último passo da desidratação foi substituída por uma mistura de TBA e parafina líquida (1:1), deixando o material por duas horas nessa mistura.

O material foi transportado para as pequenas fôrmas de alumínio devidamente etiquetadas e contendo $3 / 4$ de sua capacidade com parafina histológica fundida (ponto de fusão 56 a $58^{\circ} \mathrm{C}$ ). Elas foram levadas à estufa $\left(60^{\circ} \mathrm{C}\right)$ por 12 horas. Passado este tempo, a parafina pura foi substituída por outra e novamente levada à estufa por quatro horas, após o que foi realizada nova troca. Decorridas mais quatro horas, as fôrmas de papel previamente preparadas foram preenchidas com parafina pura fundida, e o material vegetal foi transferido para o centro da fôrma, na posição apropriada para cortes longitudinais, sendo deixado esfriar para solidificar a parafina e formarem-se os blocos.

\section{d) Seccionamento}

O bloco foi levado ao micrótomo manual rotativo, obtendo-se tiras de parafina com $12 \mu \mathrm{m}$ de espessura, contendo os cortes histológicos, para posterior montagem das lâminas.

\section{e)Montagem das seç̧ões}

As secções nas tiras de parafina foram montadas em lâminas de vidro 26 x 76mm. Aplicouse uma fina camada de um adesivo constituído de 
albumina diluída em água (duas gotas em $50 \mathrm{~mL}$ de água) com auxílio de um pincel. Após a aplicação do adesivo nas lâminas, as secções sequenciadas dos segmentos nas tiras de parafina foram colocadas sobre as lâminas e estiradas em chapa aquecida a $40^{\circ} \mathrm{C}$. O excesso de albumina foi removido com papel de filtro, e as lâminas foram identificadas e deixadas para secar por 48 horas em repouso.

\section{f)Coloração}

A coloração abrange as etapas de desparafinização (passos 1 a 8), coloração (9 e 10), nova desidratação (11 e 19) e sobreposição das lamínulas. As secções foram contrastadas pela coloração com Safranina O, cujos passos, soluções e tempo utilizados se encontram descritos na Tabela 2.

No último procedimento da coloração, as lâminas foram retiradas uma por vez do xilol e aplicaram-se, imediatamente, com o auxílio de um bastão de vidro, 1 a 2 gotas de Bálsamo do Canadá, sobrepondo-se à lamínula de $24 \times 60 \mathrm{~mm}$. Após secarem por 15 dias, as amostras foram selecionadas em microscópio óptico e depois fotomicrografadas no mesmo.

\section{RESULTADOS E DISCUSSÃO}

Analisando-se as fotomicrografias da Figura 1, observa-se, em A, a região da enxertia sobre $P$. coccinea, um mês após a realização da enxertia, mostrando tecidos vasculares já regenerados e a conexão efetuada entre os tecidos do enxerto e porta-enxerto. Em B, vê-se, em maior detalhe, a linha de união entre enxerto e porta-enxerto (P. coccinea), apresentando tecidos crescendo justapostos, tecidos vasculares regenerados e massa de células parenquimáticas, responsáveis pela atividade meristemática de formação dos novos tecidos. Observam-se as origens dos tecidos do enxerto ( $P$. edulis f. flavicarpa) e os tecidos originados do porta-enxerto ( $P$. coccinea), pelas diferenças apresentadas pelos tecidos de ambos. Ainda, pode-se constatar que estes tecidos crescem justapostos, não havendo fusão entre eles, comportamento semelhante ao observado por Abreu et al. (2003) e Nunes et al. (1999) na microenxertia por cultura de tecidos em macieira.

Também na Figura 1, observa-se, na fotomicrografia $\mathrm{C}$, detalhe da região da enxertia sobre P. edulis f. flavicarpa, apresentando abundante tecido parenquimático e tecidos vasculares conectados, restabelecendo-se o fluxo de seivas. Em D, têm-se maior detalhe da linha de união entre enxerto e portaenxerto (P. edulis f. flavicarpa), mostrando a zona de conexão dos tecidos vasculares.

Observando-se as fotomicrografias da Figura 2, em E, visualiza-se, na extremidade superior da fenda do porta-enxerto de P. edulis f. flavicarpa, abundância de tecido meristemático em diferenciação, tecidos do córtex e tecidos vasculares. Em $\mathrm{F}$, apresenta-se em maior detalhe a extremidade superior da fenda do porta-enxerto de P. edulis f. flavicarpa, observando-se tecido meristemático diferenciando-se em tecido vascular junto aos antigos tecidos da fenda do porta-enxerto. Na fotomicrografia $\mathrm{G}$, tem-se o tecido meristemático diferenciando-se em tecidos vasculares junto aos tecidos vasculares da fenda de $P$. giberti. O que pode ser observado em maior detalhe em $\mathrm{H}$, em ângulo visual da esquerda para a direita, são células de tecido meristemático diferenciando-se em células de tecidos vasculares; nota-se que, em princípio, elas têm a forma mais esférica e que, aos poucos, vão alongando-se, ficando cilíndricas, até se tornarem células de vaso junto aos tecidos vasculares da fenda de $P$. giberti, conforme foi observado também noutras frutíferas por Pio et al. (2001), Estrada-Luna et al. (2002), Ribeiro et al. (2008) e Navarro et al. (1988).

Estudando-se as fotomicrografias da Figura 3, observam-se, em I, na região da enxertia sobre $P$. edulis f. flavicarpa, tecidos vasculares já regenerados e conectados. Nota-se que, por ocasião da enxertia, os tecidos vasculares não ficaram exatamente justapostos; entretanto, isto não inviabilizou a formação da união da enxertia na muda, verificandose reordenação de direção dos tecidos vasculares de forma a tocar-se para conexão. Este fato conferiu um perfil sinuoso aos tecidos vasculares na altura da linha de união enxerto/porta-enxerto, visto em maior detalhe em J. Fatos semelhantes foram observados por Oliveira (2002), trabalhando com enxertia em citros por substituição de ápice caulinar, concluindo ainda que, se o enxerto e o porta-enxerto não tenham sido completamente justapostos, os tecidos vasculares internos ordenam-se para uma solução de continuidade. Isso ocorre também na microenxertia (RAHARJO ; LITZ, 2005) e apresenta a vantagem da superação do período de juvenilidade, que ocorre na propagação por semente (LIMA et al., 2006).

$\mathrm{Na}$ fotomicrografia K, observa-se, na região da enxertia sobre $P$. alata, uma estrutura similar a um primórdio radicular, acima da linha de união enxerto/porta-enxerto, o que pode ser observado em maior detalhe em L. Tal estrutura pode ter tido duas origens: primeiro, ela foi pré-formada e estava latente no caule do enxerto, passando a desenvolverse após a operação de enxertia. Ou, segundo, os cortes efetuados no enxerto, por ocasião da enxertia, 
estimularam a formação de raiz adventícia, como ocorre na estaquia (NAVARRO et al., 1975; MAYER et al., 2006; RIBEIRO et al., 2008; KAWAGUCHI et al., 2008). Entretanto, qualquer que tenha sido a sua origem, sua presença neste caso é indesejável, pois, quando se desenvolver, a raiz por ele originada atingirá o solo e eliminará o isolamento entre copa e patógenos do solo, pretendido com o uso do portaenxerto. Dessa forma, caso haja brotações de raiz a partir do enxerto de alguma muda, deve-se proceder uma poda destas raízes originadas na copa.

TABELA 1 - Série gradual de alcoóis utilizada na desidratação da região da enxertia, abrangendo parte do caule do enxerto e porta-enxerto de maracujá.

\begin{tabular}{ccccccc}
\hline \multirow{2}{*}{ Passos } & $\begin{array}{c}\text { Álcool } \\
(\%)\end{array}$ & Tempo (h) & $\begin{array}{c}\text { Agua } \\
\text { destilada }\end{array}$ & Etanol 95\% & Etanol 100\% & TBA 100\% \\
\hline 1 & 70 & 2 & 30 & 50 & 0 & 20 \\
2 & 85 & 2 & 15 & 50 & 0 & 35 \\
3 & 95 & 2 & 0 & 45 & 0 & 55 \\
4 & 100 & 2 & 0 & 0 & 25 & 75 \\
5 & 100 & 24 & 0 & 0 & 0 & 100 \\
6 & 100 & 24 & 0 & 0 & 0 & 100 \\
7 & 100 & 24 & 0 & 0 & 0 & 100 \\
\hline
\end{tabular}

TABELA 2 - Coloração utilizada na preparação das lâminas histológicas para o estudo da regeneração dos tecidos, na região da enxertia, abrangendo parte do caule do enxerto e porta-enxerto, um mês após a realização da enxertia hipocotiledonar em maracujá.

\begin{tabular}{ccc}
\hline Passos & Soluções & Tempo (minutos) \\
\hline 1 & Xilol & 10 \\
2 & Xilol & 10 \\
3 & Xilol & 10 \\
4 & Xilol - Etanol absoluto (1:1) & 5 \\
5 & Etanol (100\%) & 5 \\
6 & Etanol (100\%) & 5 \\
7 & Etanol (95\%) & 5 \\
8 & Etanol (80\%) & 5 \\
9 & Safranina O & 30 \\
10 & Lavagem em água corrente & $3-5$ \\
11 & Etanol (90\%) & $2-3$ \\
12 & Etanol (95\%) & $2-3$ \\
13 & Etanol (100\%) & $2-3$ \\
14 & Etanol (100\%) & $2-3$ \\
15 & Etanol + Xilol (3:1) & 3 \\
16 & Etanol + Xilol (1:1) & 3 \\
17 & Etanol + Xilol (1:3) & 3 \\
18 & Xilol & 5 \\
19 & Xilol & 5 \\
\hline
\end{tabular}



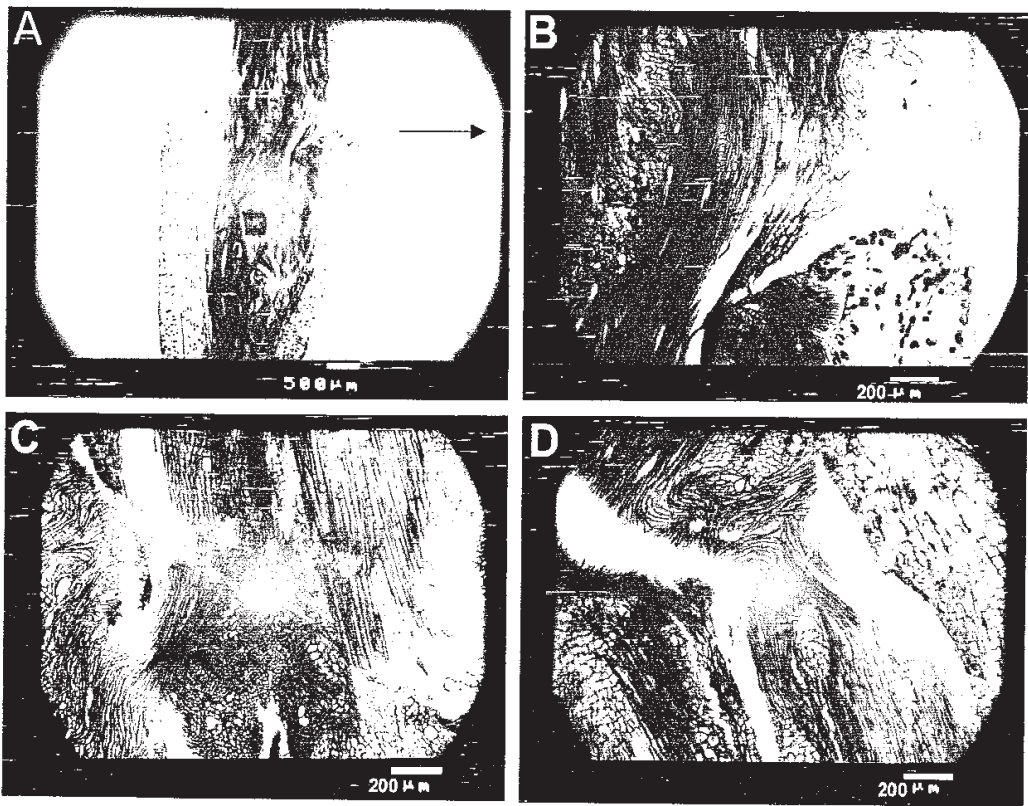

FIGURA 1 - Fotomicrografias de secções histológicas da região da enxertia hipocotiledonar de maracujazeiroamarelo sobre os porta-enxertos Passiflora coccinea e P. edulis f. flavicarpa. A) Região da enxertia sobre $P$. coccinea mostrando tecidos vasculares já regenerados. B) Detalhe da linha de união entre enxerto e porta-enxerto ( $P$. coccinea). C) Região da enxertia sobre $P$. edulis $\mathrm{f}$. flavicarpa apresentando abundante tecido parenquimático e tecidos vasculares reconectados. D) Linha de união entre enxerto e porta-enxerto (P. edulis f. flavicarpa) mostrando a zona de conexão dos tecidos vasculares.
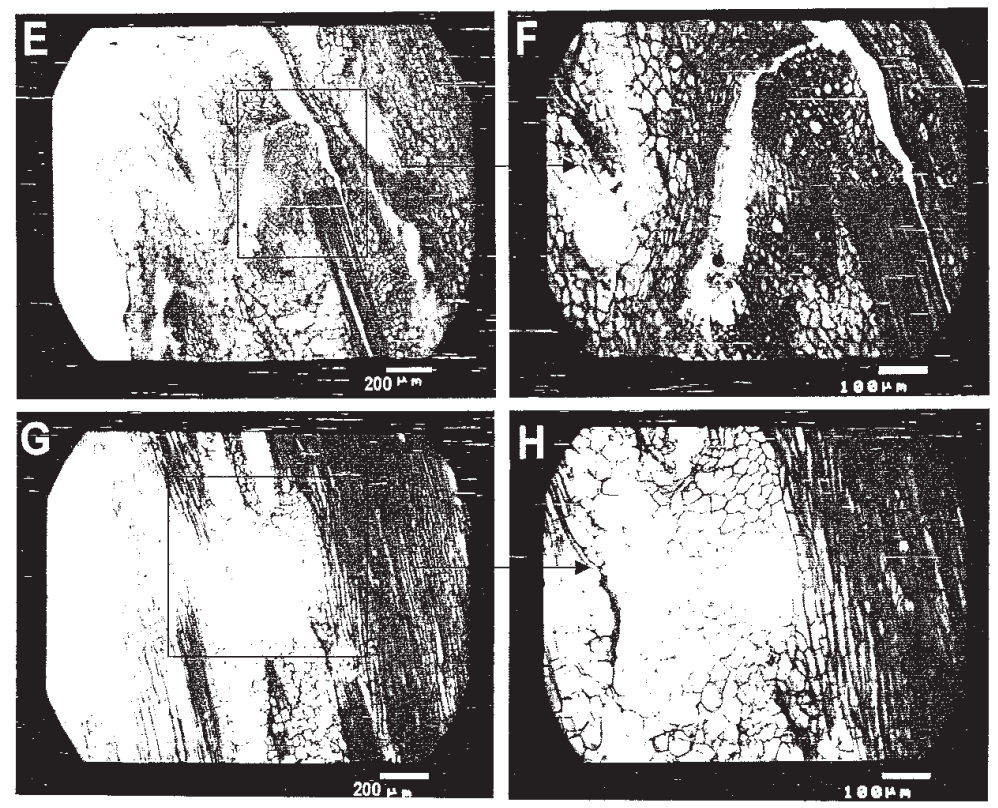

FIGURA 2- Fotomicrografias de secções histológicas da região da enxertia hipocotiledonar de maracujazeiroamarelo sobre os porta-enxertos Passiflora edulis f.flavicarpa e P. giberti. E) Região da enxertia sobre $P$. edulis f. flavicarpa mostrando a extremidade superior da fenda do porta-enxerto. F) Detalhe da extremidade superior da fenda do porta-enxerto de P.edulis f. flavicarpa. G) Região da enxertia sobre P. giberti mostrando tecido meristemático e tecidos vasculares da fenda. $\mathrm{H}$ ) Detalhe de tecido meristemático e tecidos vasculares da fenda de P. giberti. 

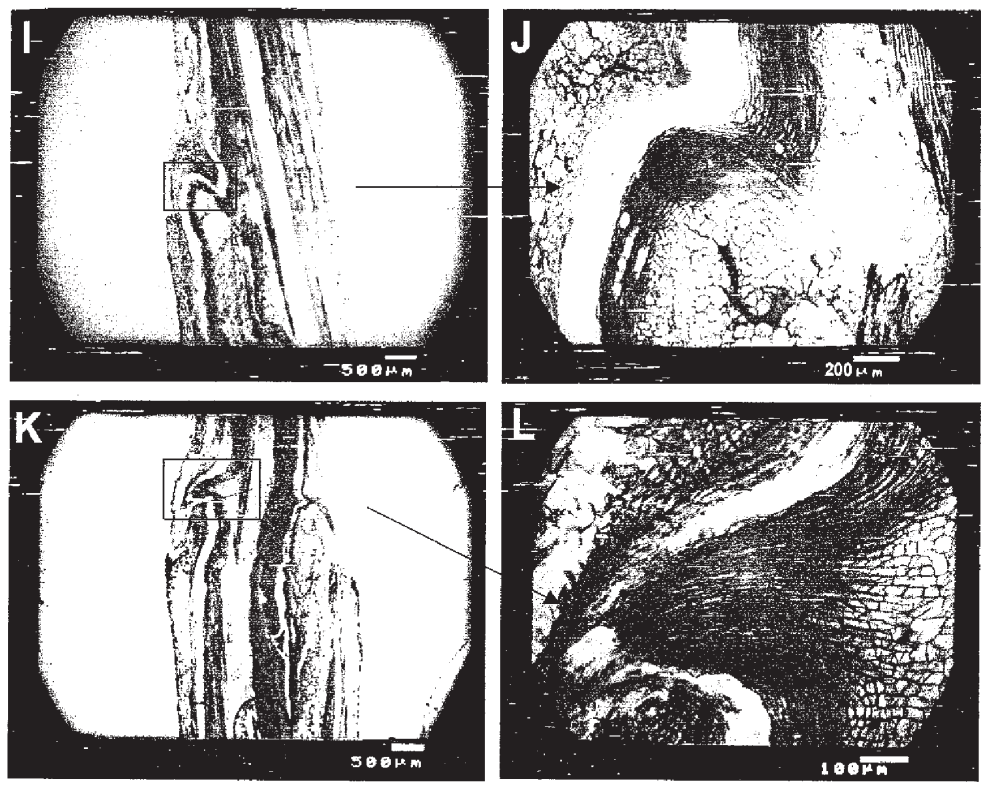

FIGURA 3 - Fotomicrografias de secções histológicas da região da enxertia hipocotiledonar de maracujazeiroamarelo sobre os porta-enxertos Passiflora edulis f. flavicarpa e P. alata. I) Região da enxertia sobre P. edulis f. flavicarpa mostrando tecidos vasculares já regenerados. J) Detalhe da região da enxertia sobre $P$. edulis f. flavicarpa mostrando tecidos vasculares já regenerados. K) Região da enxertia sobre $P$. alata mostrando primórdio radicular no enxerto acima da linha de união enxerto/porta-enxerto. M) Detalhe de primórdio radicular no enxerto sobre $P$. alata.

\section{CONCLUSÕES}

Nas condições em que o experimento foi realizado, verifica-se similaridade anatômica na formação da união da enxertia entre os sete portaenxertos. Um mês após a realização da enxertia, a conexão entre os tecidos vasculares do enxerto e do porta-enxerto já tinha-se realizado.

\section{REFERÊNCIAS}

ABREU, M.F. de; NUNES, J. C. de O.; SANTOS, M. ; PEDROTTI, E. L. Estudos histológicos preliminares da microenxertia de plantas micropropagadas de macieira. Revista Brasileira de Fruticultura, Jaboticabal, v. 25, n. 1, p. 195196, 2003.

ESAU, K. Anatomia das plantas com sementes. São Paulo: Edgard Blücher, 1974. p. 293.
ESTRADA-LUNA, A.A.; LÓPEZ-PERALTA, C.; CÁRDENAS-SORIANO, E. In vitro micrografting and the histology of graft union formation of selected species of prickly pear cactus (Opuntia sp). Scientia Horticulturae, Amsterdam, v.92, p.317-327, 2002.

JANICK, J. A ciência da horticultura. Rio de Janeiro: Freitas Bastos, 1966. p. 485.

JOHANSEN, D. A. Plant microtechnique. New YorK: Mc Graw-Hill BooK, 1940. p. 523.

KAWAGUCHI, M.; TAJI, A.; BACKHOUSE, D.; ODA, M. Anatomy and physiology of graft incompatibility in solanaceous plants. Journal of Horticultural Science \& Biotechnology, Ashford, v.83, p.581-588, 2008.

LIMA, A. de A.; CALDAS, R.C.; SANTOS, V. da S. Germinação e crescimento de espécies de maracujá. Revista Brasileira de Fruticultura, Jaboticabal, v.28, n.1, p.125-127, 2006. 
MAYER, J.L.S.; BIASI, L.A.; BONA, C. Capacidade de enraizamento de estacas de quatro cultivares de Vitis L. (Vitaceae) relacionada com os aspectos anatômicos. Acta Botânica Brasilica, Porto Alegre, v.20, p.563-568, 2006.

NAVARRO, L. Application of shoot-tip grafting in vitro to woody espécies. Acta Horticulturae, The Hague, v. 227, p.43-55, 1988.

NAVARRO, L.; ROISTACHER, C.N.; MURASHIGE, T. Improvement of shoot-tip grafting in vitro for virus-fre Citrus. Journal of the American Society for Horticultural Science, Alexandria, v. 100, p.471-479, 1975.

NUNES, J.C.O.; BARPP, A.; SILVA, F.C.; PEDROTTI, E.L. Micropropagação do porta-enxerto 'Marubakaido' (Malus prunifolia), a partir da cultura de meristemas. Revista Brasileira de Fruticultura, Jaboticabal, v.21, n.2, p.191-195, 1999.

OLIVEIRA, I. V. M. Enxertia em citros por substituição de ápice caulinar. 2002 32f. Dissertação (Mestrado em Genética e Melhoramento de Plantas) - Faculdade de Ciências Agrárias e Veterinárias, Universidade Estadual Paulista, Jaboticabal, 2002.
OLIVEIRA, I.V.M.; DAMIÃO FILHO, C.F.; CARVALHO, S.A. Enxertia em citros por substituição de ápice caulinar. Revista Brasileira de Fruticultura, Jaboticabal, v. 24, n. 3, p. 744747, 2002.

PIO, R.; CASTRO, E. M. de; GAVILANES, M. L.; RIBEIRO, W. G. Características anatômicas de porta-enxertos para microenxertia em diferentes alturas. Ciência e Agrotecnologia, Lavras, MG, v.25, p.848-852, 2001

RAHARJO S. H.T.; LITZ R. E. Micrografting and ex vitro grafting for somatic embryo rescue and plant recovery in avocado (Persea americana). Plant Cell, Tissue and Organ Culture, The Hague, v. 82, p.1-9, 2005.

RIBEIRO, L.M.; PEIXOTO, J.R.; ANDRADE, S.R.M. de; FONSECA, R.S.; VIEIRA, L.M.; PEREIRA, W.V.S. Microenxertia ex vitro para eliminação do vírus CABMV em maracujá-azedo. Pesquisa Agropecuária Brasileira, Brasília, v.43, p.589594, 2008. 